\title{
Helicobacter pylori bacteria alter the p53 stress response via Erk-HDM2 pathway
}

\author{
Vikas Bhardwaj, ${ }^{1,2}$, Jennifer M. Noto ${ }^{4}$ Jinxiong Wei ${ }^{1,2}$, Claudia Andl ${ }^{2,3}$, \\ Wael EI-Rifai ${ }^{2,3}$, Richard M. Peek ${ }^{3,4}$, Alexander I. Zaika1,2,3 \\ ${ }^{1}$ Department of Veterans Affairs, Tennessee Valley Healthcare System, Nashville, Tennessee, USA \\ ${ }^{2}$ Department of Surgery, Vanderbilt University Medical Center and Vanderbilt-Ingram Cancer Center, Nashville, \\ Tennessee, USA \\ ${ }^{3}$ Department of Cancer Biology, Vanderbilt University Medical Center and Vanderbilt-Ingram Cancer Center, Nashville, \\ Tennessee, USA \\ ${ }^{4}$ Division of Gastroenterology, Vanderbilt University Medical Center and Vanderbilt-Ingram Cancer Center, Nashville, \\ Tennessee, USA
}

Correspondence to:

Alexander I. Zaika, e-mail: alex.zaika@vanderbilt.edu

Keywords: p53, Helicobacter pylori, gastric tumor, HDM2, CagA

Abbreviations: CagA - cytotoxin-associated gene A, MOI - Multiplicity of Infection

Received: August 5, 2014

Accepted: November 26, 2014

Published: January 22, 2015

\section{ABSTRACT}

$H$. pylori infection is the strongest known risk factor for gastric cancer. Inhibition of host tumor suppressor mechanisms by the bacteria underlies the development of this disease. Among the tumor suppressors affected by $\mathrm{H}$. pylori are p53 and E-cadherin, which inhibition has been shown to increase the risk of gastric cancer. In this report, we investigated the interaction between E-cadherin and p53 in $\mathrm{H}$. pyloriinfected cells. We found that downregulation of E-cadherin leads to cellular stress and activation of p53. In the setting of $H$. pylori infection, this mechanism, however, is disrupted. We found that although co-culture of gastric epithelial cells with $H$. pylori led to downregulation of E-cadherin and cellular stress, it resulted in inhibition of p53, which is mediated by intracellular Erk kinases and HDM2 protein induced by $H$. pylori. Experimental inhibition of HDM2/p53 interactions restored p53 activity, and decreased survival of infected cells. Collectively, our results revealed that regulation of p53 and E-cadherin is tightly linked through the p53 stress response mechanism that is inhibited by $H$. pylori via activation of Erk1/2-HDM2-p53 pathway leading to survival of damaged cells. This might be advantageous to the bacteria but may increase the cancer risk.

\section{INTRODUCTION}

Approximately half of the world's population is infected with the bacterial pathogen Helicobacter pylori (H. pylori). Gastric colonization by H. pylori is the major cause of chronic gastritis and peptic ulcer disease, and is the strongest known risk factor for gastric adenocarcinoma (GC), which remains one of the most common forms of cancer and one of the leading causes of cancer-related death worldwide [1]. Interplay between host and bacterial factors plays a defining role in the development of gastric malignancy [2]. One of the best characterized bacterial virulence determinants known to increase the risk of gastric cancer is the cag pathogenicity island (cagPAI) [3]. The cagPAI is a bacterial genetic locus that encodes the type IV secretion system (T4SS), which is required for delivery of bacterial protein CagA into host cells. Following intracellular injection through the T4SS, CagA protein is phosphorylated by host kinases and alters the cell signaling machinery in ways that are thought to be beneficial to the bacteria. CagA was found to behave as a bacterial oncoprotein inducing gastric tumor in mice when it was transgenically overexpressed [4]. It has been shown that multiple oncogenic pathways such as PI3K/Akt, Wnt/ $\beta$-catenin and Ras/Erk are activated by CagA and other bacterial factors. 
The aberrant activation of these oncogenes is counteracted by cellular tumor suppressors such as p53. p53 protein is accumulated in stress conditions and activates transcription of multiple p53 targets that halt abnormal proliferation of cells that otherwise may become tumorigenic $[5,6]$. The p53 gene $(t p 53)$ is the most commonly mutated gene in gastric tumor. Approximately $40-50 \%$ of gastric cancer patients carry inactivating mutations in the p53 gene. H. pylori infection has been reported to enhance mutagenesis of p53 [7]. However, recent studies have also shown that $H$. pylori can cause non-mutational inactivation of p53 $[8,9]$.

$H$. pylori has been shown to preferentially attach to gastric epithelial cells in close proximity to the apical junctional complexes [10]. Bacterial attachment has been suggested to disrupt the epithelial barrier and possibly provide the bacteria with essential nutrients or access to the lamina propria [11]. Disruption of the epithelial barrier involves alteration of the components of the junctional complexes including E-cadherin [12]. E-cadherin is a component of the adherens junctions that regulates cellcell adhesion, intracellular signaling, cell polarity, and proliferation $[10,13]$. H. pylori infection has shown to acutely cleave E-cadherin and disrupt the adherens junctions $[14,15]$. H. pylori infection can also decrease expression of E-cadherin by promoting hypermethylation of the E-cadherin gene $(C D H 1)$ that can be reversed by eradication of the bacteria [16-18]. The E-cadherin gene $(\mathrm{CDH} 1)$ was found to be frequently mutated in diffuse type of gastric tumor, implying that E-cadherin inactivation is important for gastric cancer development [19]. However, animal studies have found that downregulation of E-cadherin alone is not sufficient to cause gastric tumor. In addition to E-cadherin, inactivation of p53 is required for development of gastric malignancy in mice [20]. E-cadherin and p53 mutations have also been shown to increase predisposition to gastric cancer in human [21, 22]. In this study, we investigated the interaction between $\mathrm{p} 53$ and E-cadherin in H. pylori-infected cells.

\section{RESULTS}

\section{H. pylori decreases E-cadherin protein levels}

As a prelude to defining the role of p53-E-cadherin interactions, we initially sought to characterize the regulation of E-cadherin in Mongolian gerbils infected with $H$. pylori. Mongolian gerbils were inoculated with H. pylori strain 7.13 for 6 hours and then gastric tissues were collected and analyzed for E-cadherin expression by Western blotting. We found that E-cadherin protein levels were significantly decreased following infection of Mongolian gerbil with $H$. pylori (Figure 1A). To determine the effects of $H$. pylori on gastric epithelial cells in a more controlled environment, we first analyzed expression of
E-cadherin protein in a panel of gastric epithelial cells harboring wild-type p53 (AGS, HFE145, SNU1, STKM2 and $\mathrm{mGEC}$ ). Detectable levels of E-cadherin were only observed in STKM2 and mGEC cells (Supplementary Figure 1A). STKM2 cells and mGECs were then co-cultured with $H$. pylori strain 7.13 at a bacteria-to-cell ratio of 100:1 for 24 hours and analyzed for alterations in E-cadherin protein levels. We found that $H$. pylori strongly reduces the levels of E-cadherin in both STKM2 and $\mathrm{mGEC}$ cells (Figure 1B). Since mGECs express SV40 large T-antigen that may affect regulation of p53 [23], we used STKM2 cells for our further analysis.

We next performed immunofluorescence analysis of E-cadherin protein in STKM2 cells co-cultuted with H. pylori strain 7.13 (MOI 100) for 24 hours and found that $H$. pylori disrupts intercellular adherens junctions and reduces protein levels of E-cadherin, as judged by a decrease in intensity of fluorescence (Figure 1C). Combined, our results show that $H$. pylori acutely downregulates E-cadherin levels and disrupts cellular adherens junctions in our model system.

\section{Inhibition of E-cadherin activates p53}

To investigate how downregulation of E-cadherin affects p53, STKM2 cells were transfected with E-cadherin siRNA and analyzed for expression of p53. p53 protein was found to be strongly induced in response to E-cadherin downregulation (Figure 2A). Notably, this induction of $\mathrm{p} 53$ was not accompanied by changes in levels of p53 mRNA, indicating that p53 protein is regulated by post-translational mechanisms (Figure 2B). To analyze how downregulation of E-cadherin affects activity of p53, we employed a reporter assay. STKM2 cells treated with control or E-cadherin siRNAs for 24 hours were transfected with p53 luciferase reporter PG13-Luc and analyzed for p53 activity. We found that inhibition of E-cadherin significantly activates the p53 reporter (Figure 2C). Downregulation of E-cadherin was also accompanied by an increase in protein levels of p53 transcriptional targets PUMA and p21/WAF1, further showing that p53 becomes activated (Figure 2D). To analyze the functional role of p53 activation, we performed cell cycle analysis after E-cadherin downregulation using flow cytometry. We found that inhibition of E-cadherin leads to cellular stress and G1/S cell cycle arrest (Figure 2E) but does not result in apoptosis (Supplementary Figure 1B).

To investigate the mechanism of p53 induction, STKM2 cells transfected with E-cadherin siRNA were treated with specific chemical inhibitors that affect upstream regulators of p53. Protein lysates were collected 12 hours after treatment and analyzed for expression of p53 protein using Western blotting. Among the tested compounds, p38 MAPK (SB203580) and JNK/SAPK (SP600125) inhibitors were most effective in suppression 


\section{Gerbils}
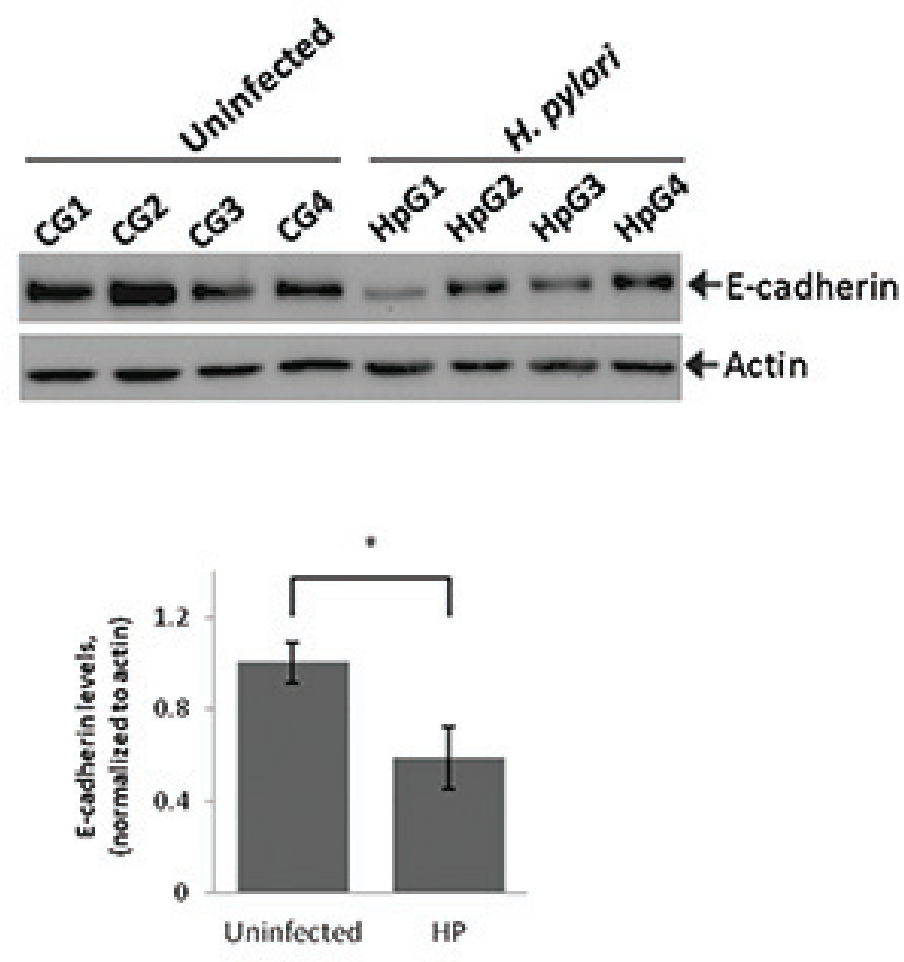

c

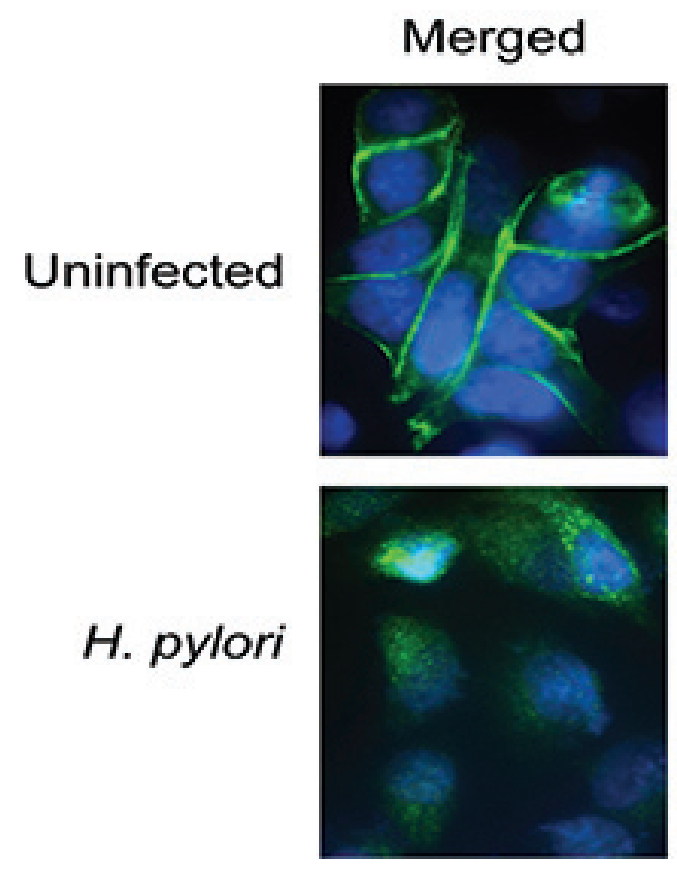

E-cadherin
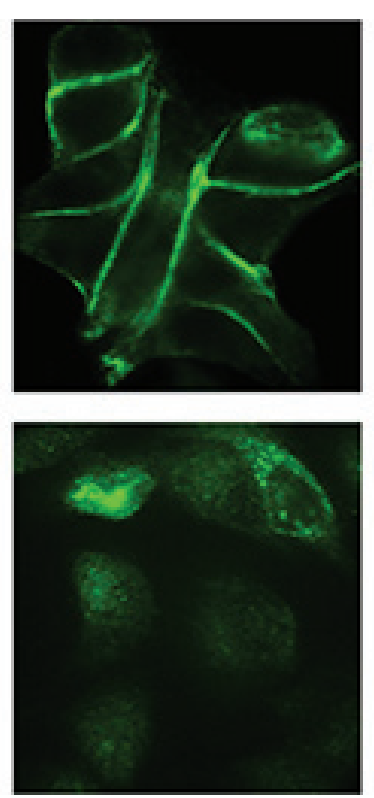

mGEC

Hp:
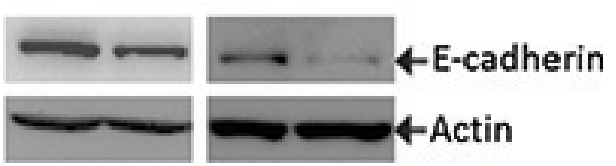

Figure 1: H. pylori downregulates E-cadherin protein in vitro and in vivo. (A) Lysates were prepared from gastric tissues collected from Mongolian gerbils infected with $H$. pylori strain 7.13 for 6 hrs or left uninfected and analyzed using Western blotting. Actin was used as a loading control. Protein levels of E-cadherin were quantified by densitometry and compared between uninfected (CG1... CG4) and H. pylori-infected (HpG1...HpG4) groups of animals $\left({ }^{*}, p<0.05\right)$. (B) E-cadherin protein was analyzed in STKM2 and mGEC cells co-cultured with $H$. pylori strain 7.13 for 24 hrs. (C) Immunofluorescence analysis of expression and subcellular localization of E-cadherin protein was performed in STKM2 cells co-cultured with $H$. pylori strain 7.13 for 24 hrs. A representative image is shown. 
A
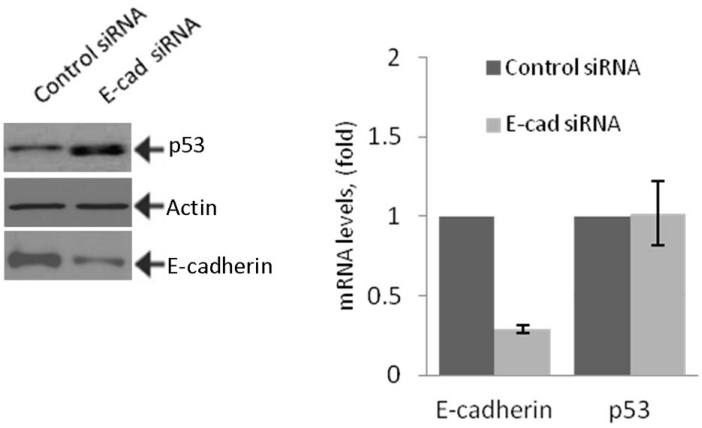

$\mathbf{E}$
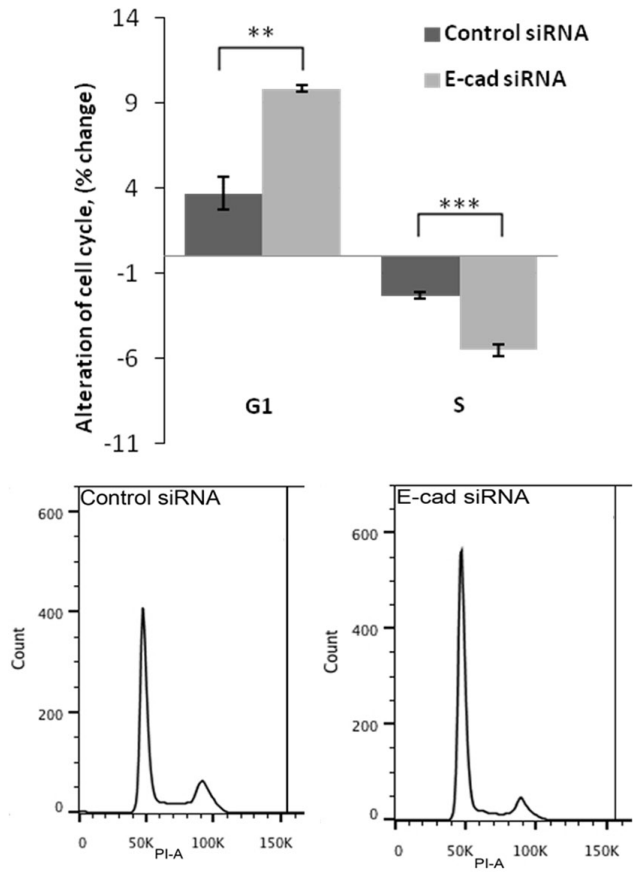

H

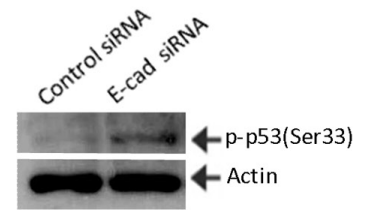

C

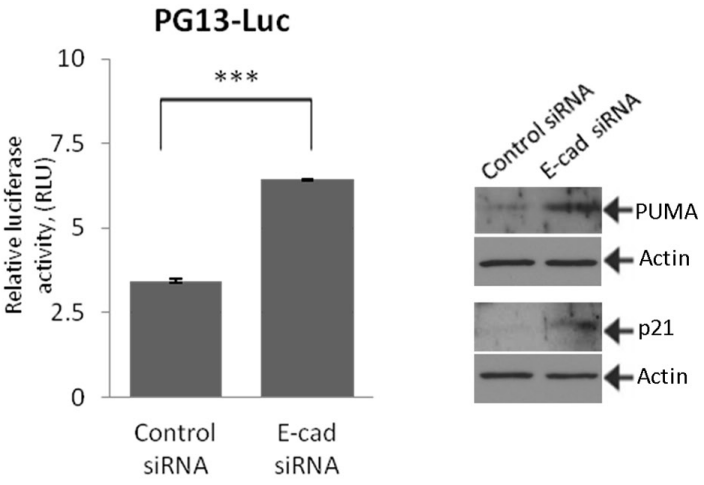

$\mathbf{F}$

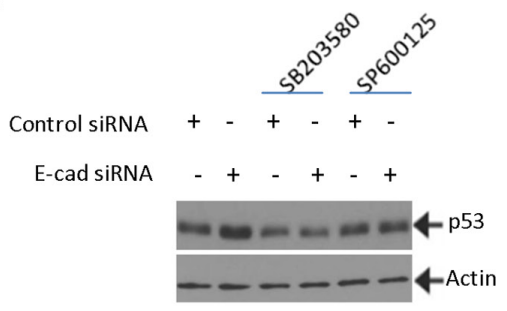

G

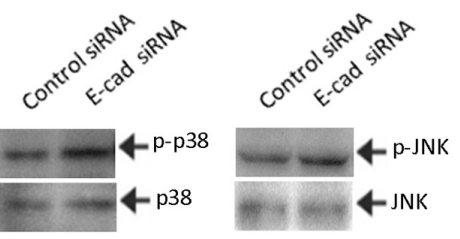

Figure 2: Inhibition of E-cadherin activates p53 and induces cell cycle arrest. (A) STKM2 cells were transfected with either specific E-cadherin or control siRNA for 48 hrs and analyzed for expression of p53 protein by Western blotting. (B) STKM2 cells transfected with either control siRNA or E-cadherin siRNA for 48 hrs were analyzed for mRNA expression of E-cadherin and p53. Data were normalized to expression of HPRT mRNA. (C) STKM2 cells treated with a scrambled control siRNA or E-cadherin siRNA for 24 hrs were co-transfected with p53 reporter plasmid (PG13-Luc) and vector expressing Renilla luciferase for an additional 24 hrs and analyzed using the dual-luciferase reporter assay (***, $p<0.001 ; n=3)$. (D) The same as (A) but protein expression of p53 transcriptional targets, p21 and PUMA, was assessed. (E) Cell cycle analysis was performed on STKM2 cells transfected with E-cadherin or control scrambled siRNA for 48 hrs by flow cytometry using propidium iodide (PI) staining $(* *, p<0.01$. ***, $p<0.001 ; n=4)$. Graph represents alterations in the G1 and S phases of the cell cycle (top panel). Bottom panels show flow cytometry profiles for STKM2 cells transfected with either control or E-cadherin siRNAs. (F) Inhibition of p38 and JNK kinases prevents induction of p53. STKM2 cells transfected with control or E-cadherin siRNAs for 36 hrs were treated with specific inhibitors $(5 \mu \mathrm{M})$ of 338 (SB203580) or JNK (SP600125) kinases for an additional $12 \mathrm{hrs}$ and analyzed for expression of p53 protein using Western blotting. (G) Phosphorylation of p38(Thr180/Tyr182) and JNK(Thr183/ Tyr185) was assessed after downregulation of E-cadherin with siRNA. (H) Phosphorylation of p53 protein at Ser33 was analyzed after downregulation of E-cadherin in STKM2 cells. 
of p53 (Figure 2F and data not shown). These stress kinases are known to directly phosphorylate and activate p53 [24, 25]. To assess the kinase regulation, their phosphorylation was analyzed after downregulation of E-cadherin with siRNA. An increased phosphorylation of both p38(Thr180/ Tyr182) and JNK(Thr183/Tyr185) kinases was found, indicating their activation (Figure $2 \mathrm{G}$ ). We also found an increased phosphorylation of p53 at position serine-33 (Ser33), a phosphorylation site regulated by p38 kinase [26], implying that E-cadherin downregulation leads to activation of stress kinases and p53 (Figure 2H).

\section{H. pylori prevents activation of $\mathrm{p53}$ and decreases its protein levels}

To investigate the effect of $H$. pylori on activation of p53, STKM2 cells in which E-cadherin was downregulated with siRNA for 24 hours were co-cultured with $H$. pylori strain 7.13 (MOI 100) for an additional 24 hours. We found that $H$. pylori completely prevents induction of p53 and further decreases E-cadherin protein levels, implying that $H$. pylori is capable of inhibiting the $\mathrm{p} 53$ response in cells in which E-cadherin was downregulated (Figure 3A). To investigate the mechanism of p53 regulation in $H$. pylori-infected cells, we first analyzed the regulation of stress kinases p38 MAPK(Thr180/Tyr182) and JNK1(Thr183/Tyr185) in STKM2 cells co-cultured with $H$. pylori strain 7.13. Analogous to experiments shown in Figure 2, we found an increase in phosphorylation of p38 and JNK1 kinases as well as p53 protein at serine 33 (Figure 3B). We also found downregulation of E-cadherin (Figure 3C). However, despite downregulation of E-cadherin and activation of the stress kinases, levels of p53 protein were decreased, showing that $H$. pylori can prevent p53 response in cells with E-cadherin downregulation (Figure 3C).

\section{A}

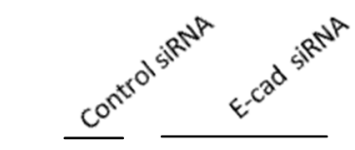

$H p:$
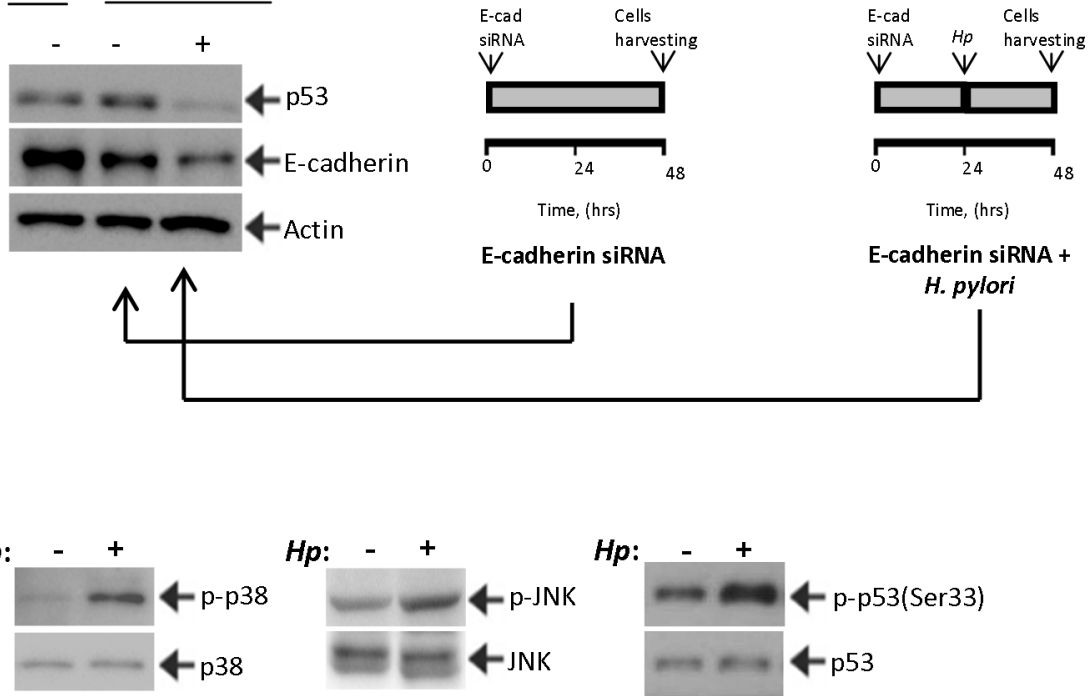

E-cadherin siRNA

$$
\text { Time, (hrs) }
$$

E-cadherin siRNA + H. pylori

B
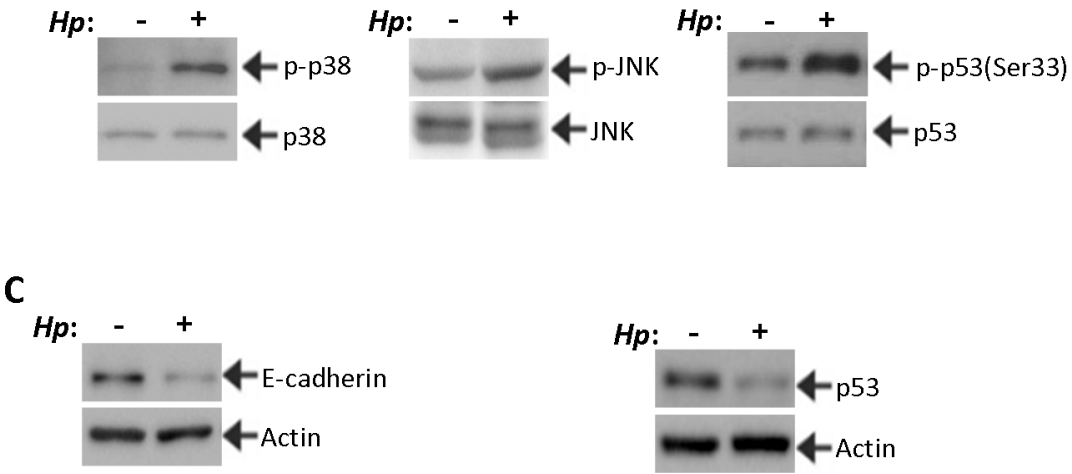

Figure 3: $\boldsymbol{H}$. pylori inhibits p53 induction. (A) H. pylori inhibits the p53 response. STKM2 cells treated with E-cadherin siRNA for $24 \mathrm{hrs}$ were co-cultured with $H$. pylori strain 7.13 for an additional $24 \mathrm{hrs}$ and analyzed for expression of p53 (left panel). The right panels illustrate the experimental design. (B) H. pylori activates p38 MAPK and JNK stress kinases. The effect of $H$. pylori strain 7.13 on phosphorylation of p38 and JNK proteins was assessed in STKM2 cells. An increased phosphorylation of p38(Tyr180/Tyr182) and JNK1(Thr183/Tyr185) was found $1.5 \mathrm{hrs}$ and $24 \mathrm{hrs}$ after co-culture with $H$. pylori, respectively. Phosphorylation of p53 protein at serine 33 was also increased. Since $H$. pylori decreases protein levels of p53, expression of p53(Ser33) was normalized to total p53 protein levels. (C) Co-culture with $H$. pylori led to downregulation of E-cadherin and p53 proteins. 


\section{p53 and E-cadherin are regulated in an HDM2- dependent manner}

Given that E3 ubiquitin ligase HDM2 is a critical regulator of $\mathrm{p} 53$ protein, we next investigated regulation of HDM2 in $H$. pylori-infected cells. We found that co-culture of STKM2 cells with $H$. pylori strain 7.13 increases the phosphorylation of HDM2 at Ser166 (Figure 4A) which is known to increase the activity of HDM2 [27, 28]. An increase in activation of HDM 2 was also found in AGS cells co-cultured with H. pylori (Figure 4A). Since AGS cells express low levels of E-cadherin (Figure Supplemental 1A), it suggests that activation of HDM2 by $H$. pylori is independent of E-cadherin expression. Interestingly, protein levels of HDM2 are dynamically decreased in $H$. pylori-infected cells and follow the degradation kinetics of p53 (Figure 4B). At the same time, a relative phosphorylation level of HDM2(Ser166) protein is steadily increased (Figure 4B, bottom panel).

To determine the role of HDM2 in H. pylori-infected cells, STKM2 cells were transfected with HDM2 specific siRNA and co-cultured with $\mathrm{H}$ pylori. Inhibition of HDM2 significantly suppressed the downregulation of $\mathrm{p} 53$ protein $(p<.05)$ induced by H. pylori (Figure 4C). We then sought to investigate the mechanisms that regulate HDM2 in H. pylori-infected cells. A previous report has shown that activation of Erk(Tyr204) increases phosphorylation of HDM2 at serine 166 [29]. We investigated the effect of H. pylori on Erk1/2 activation and found that H. pylori increases the phosphorylation of Erk2(Tyr204) in STKM2 and AGS cells (Figure 4D). We next inhibited Erk1/2 by specific siRNA for 24 hours followed by co-culture with $H$. pylori for an additional 24 hours. Our results show that downregulation of Erk $1 / 2$ significantly inhibits degradation of $\mathrm{p} 53(p<.01)$ induced by H. pylori (Figure 4E) and activates transcriptional targets p53, p21 and PUMA (Supplementary Figure 1C). Inhibition of Erk1/2 also reduces phosphorylation of HDM2(Ser166) showing that activation of Erk kinases by $H$. pylori activates HDM2, which in turn, inhibits p53 (Figure 4F).

\section{Bacterial CagA protein is involved in the regulation of $\mathrm{p53}$}

Given that injection of bacterial CagA protein plays an important role in the alteration of multiple intracellular signaling pathways, we next assessed the role of CagA in regulation of $\mathrm{p} 53$ and E-cadherin. We co-cultured STKM2 cells with wild-type $H$. pylori strain 7.13 and its isogenic $\operatorname{cag} \mathrm{A}^{-}$and $\operatorname{cag} \mathrm{E}^{-}$mutants for 24 hours (MOI 100) and analyzed for expression of p53 and E-cadherin proteins. The latter mutant is functionally similar to $7.13 \mathrm{cag}^{-}$as it does not form the T4SS that is required for delivery of CagA into host cells. The strongest inhibition of p53 was found by wild-type bacteria, while the mutants were less potent.
E-cadherin protein was downregulated by all bacterial strains, though significantly stronger inhibition was observed after co-culture with the wild-type bacteria (Figure 5A).

To further explore the role of CagA, we transfected STKM2 and AGS cells with CagA expression plasmid, cagA-pSP65SR $\alpha$. We found that CagA transfection downregulates p53 protein level in both cell lines (Figure 5B). CagA transfection also increases phosphorylation of HDM2(Ser166) protein in STKM2 and AGS cells (Figure 5C). To investigate the role of HDM2 in the CagA signaling, STKM2 cells were co-transfected with CagA and HDM2 siRNA for 40 hours and analyzed for expression of $\mathrm{p} 53$ protein. We found that, while CagA inhibits p53, downregulation of HDM2 increases p53 protein levels in CagA-transfected cells, further supporting data that degradation of $\mathrm{p} 53$ by $\mathrm{H}$. pylori is mediated by CagA and HDM2 (Figure 5D).

\section{Restoration of p53 activity increases cell death in H. pylori-infected cells}

To analyze the biological role of p53 downregulation, we inhibited HDM2 with specific chemical inhibitor Nutlin-3, which hinders the interaction of p53 with HDM2. STKM2 treated with $0.1 \mu \mathrm{M}$ or $0.5 \mu \mathrm{M}$ Nutlin-3 were co-cultured with $H$. pylori strain 7.13 for 24 hours and analyzed by Western blotting. We found that Nutlin-3 restores p53 levels and increases phosphorylation of p53 protein at Ser15 in infected cells (Figure 6A). An increase in p53 protein levels was associated with an increase in p53-dependent transcription, since Nutlin-3 treatment enhanced p53 reporter activity (PG13-Luc) and upregulated p53 transcription targets p21 and PUMA (Figure 6B, 6C). Protein levels of HDM2 were also increased (Supplementary Figure 1D). To exclude a possibility that Nutlin-3 has a toxic effect on H. pylori, CagA delivery was assessed in Nutlin-3-treated cells. As a marker for delivery of CagA, we assessed tyrosine phosphorylation of CagA protein, since CagA is specifically phosphorylated by intracellular tyrosine kinases after its injection into gastric epithelial cell [30]. Our studies found that treatment with Nutlin-3 $(0.5 \mu \mathrm{M})$ does not affect phosphorylation of CagA implying that Nutlin-3 does not have deleterious effects on $H$. pylori in these conditions (Supplementary Figure 1E). To assess how p53 restoration affects infected cells, we next performed the cell cycle analysis using flow cytometry. The effect of p53 restoration was evaluated at a MOI of 50 and MOI of 100 . We found that treatment with Nutlin-3 increases G1/S cell cycle arrest in STKM2 cells co-cultured with $H$. pylori at a MOI of 50 (Figure 6D, left panel). At a higher bacteria-to-cell ratio (MOI 100), treatment with Nutlin-3 led to significant increase in cell death (Figure 6D, right panel) showing that inhibition of p53 by H. pylori leads to better survival of infected cells. 
A

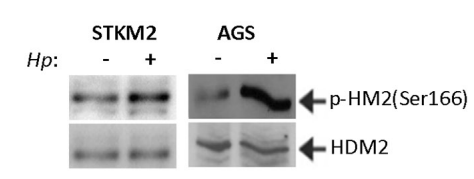

C

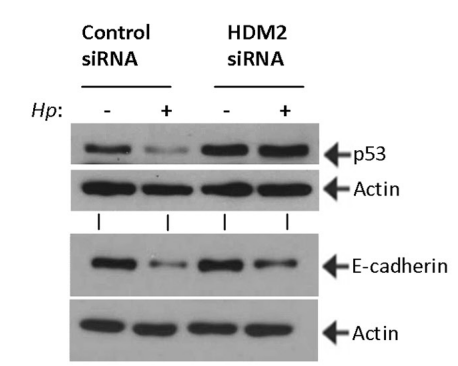

HDM2 SiRNA

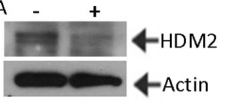

D

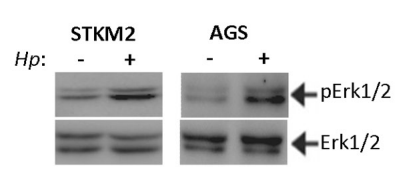

$\mathbf{F}$

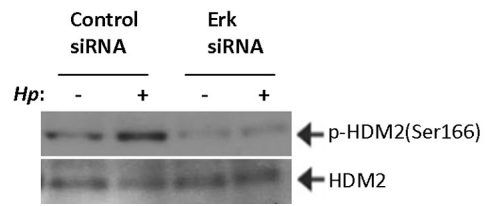

B

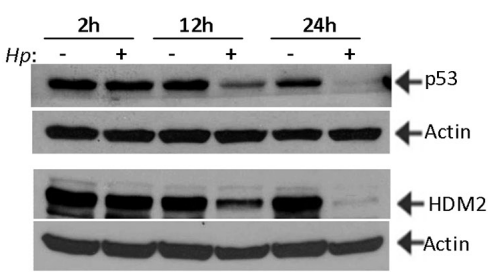

$H p: \frac{2 \mathrm{~h}}{-+} \frac{12 \mathrm{~h}}{-+}+\frac{24 \mathrm{~h}}{-+}$

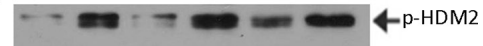

$\rightarrow$ T)

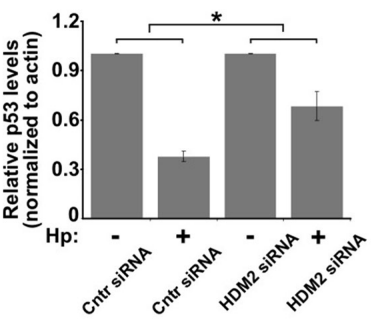

$\mathbf{E}$
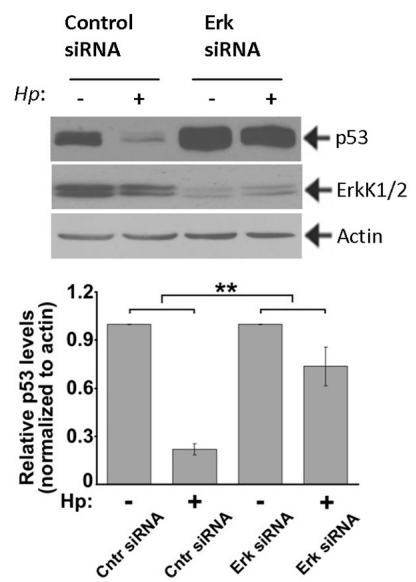

Figure 4: HDM2 regulate p53 in $\boldsymbol{H}$. pylori-infected cells. (A) H. pylori increases phosphorylation of HDM2 protein. Effect of H. pylori on phosphorylation of HDM2(Ser166) was analyzed in STKM2 and AGS cells co-cultured with H. pylori strain 7.13 for 8 hrs. Phosphorylation of HDM2 was normalized to total HDM2 protein levels. (B) Protein levels of HDM2 are dynamically changed in H. pylori-infected cells and follow kinetics that are similar to those of $\mathrm{p} 53$. At the same time, relative phosphorylation levels of HDM2(Ser166) protein are strongly increased. (C) Downregulation of HDM2 with specific siRNA inhibits degradation of p53 protein induced by H. pylori $(p<0.05$; mean $\pm \mathrm{SEM} ; n=3)$. Expression of $\mathrm{p} 53$ protein was quantified by densitometry, normalized to actin and arbitrarily set at 1 in uninfected cells. STKM2 cells were transfected with HDM2 siRNA for 24 hrs followed by co-culture with H. pylori strain 7.13 for additional $24 \mathrm{hrs}$ and then analyzed for expression of p53 and E-cadherin proteins. Bottom panel shows inhibition of HDM2 protein by siRNA. (D) The effect of H. pylori on phosphorylation of Erk1/2(Tyr204) was analyzed in STKM2 and AGS cells co-cultured with H. pylori strain 7.13 for $4 \mathrm{hrs}$. Levels of phosphorylated Erk 1/2 kinases were normalized to total levels of Erk 1/2 proteins. (E) Downregulation of Erk1/2 kinases leads to significant inhibition of $\mathrm{p} 53$ degradation $(p<.01$; mean $\pm \mathrm{SEM} ; n=4)$ by H. pylori. AGS cells treated with Erk1/2 siRNA for 24 hrs were co-cultured with H. pylori strain J166 for an additional 24 hrs and analyzed for protein expression of p53 and Erk $1 / 2$ by Western blotting. Expression of p53 protein was quantified by densitometry and normalized to actin expression (bottom panel). Expression of p53 in control uninfected cells was arbitrarily set at 1. (F) The effect of Erk1/2 inhibition on protein phosphorylation of HDM2(Ser166) in AGS cells co-cultured with H. pylori strain J166 was assessed using Western blotting. Phosphorylation of HDM2 was normalized to total HDM2 protein levels. 
A

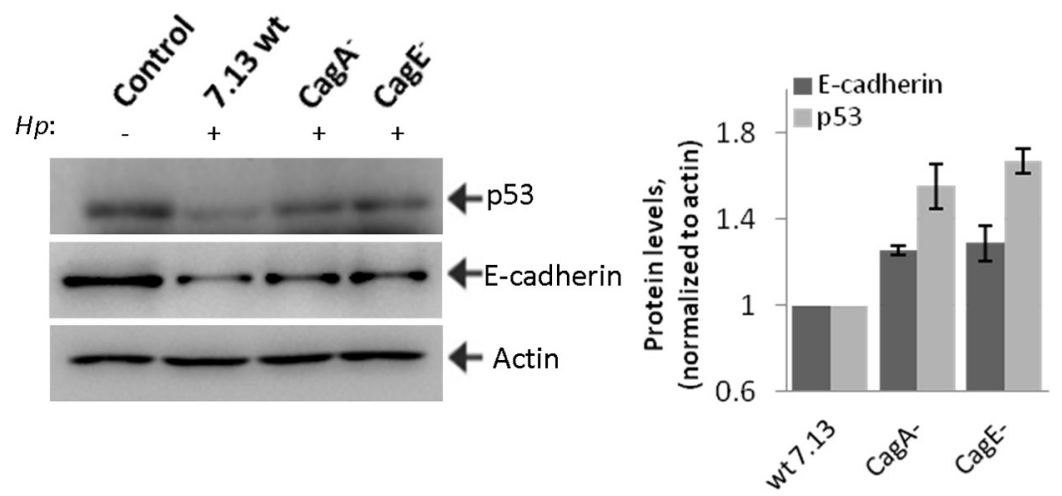

B

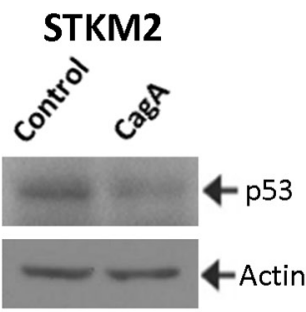

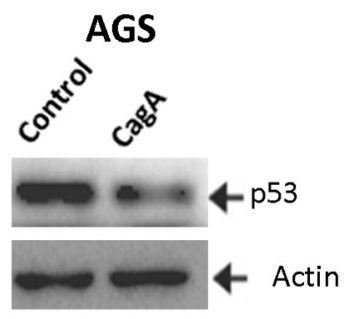

C

D

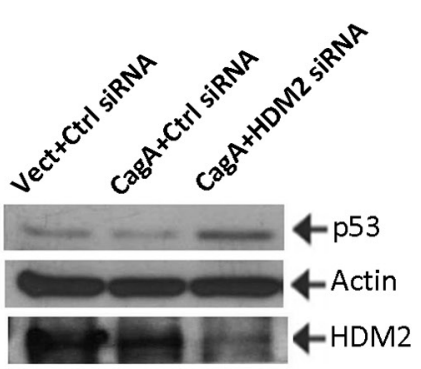

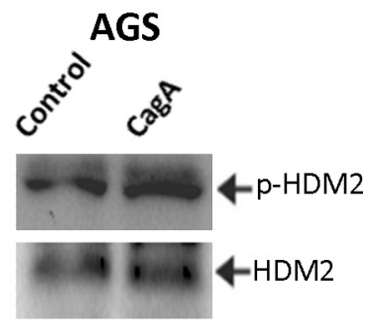

Figure 5: CagA is involved in the regulation of HDM2 and p53 proteins in $\mathrm{H}$. pylori-infected cells. (A) Cell lysates were collected from STKM2 cells co-cultured with wild type H. pylori strain 7.13 or its isogenic mutants cagA- and cagE- for 24 hrs and analyzed for protein expression of p53 and E-cadherin. Right panel shows densitometric quantifications of p53 and E-cadherin proteins. (B) STKM2 and AGS cells were transfected with CagA-expressing plasmid, cagA-pSP65SR $\alpha$, for $24 \mathrm{hrs}$ and analyzed for expression of p53 protein. (C) The same as (B) but phosphorylation of HDM2 protein was analyzed. (D) STKM2 cells were co-transfected with the indicated plasmids (empty vector or $\mathrm{CagA}$ ) and either scrambled siRNA or HDM2 siRNA for $40 \mathrm{hrs}$ and then analyzed for expression of p53 and HDM2 proteins. Bottom panel shows inhibition of HDM2 protein by siRNA.

\section{DISCUSSION}

Here we report that $H$. pylori can modulate the p53 response in stress conditions caused by targeted disruption of adherens junctions by H. pylori bacteria. We found that when E-cadherin is experimentally downregulated in gastric epithelial cells, it leads to strong cellular stress, activation of p53, induction of p53 transcription targets (p21/Waf1, PUMA), and G1/S cell cycle arrest. This process is mediated by induction of stress kinases p38 MAPK and JNK/SAPK, which have been previously reported to directly phosphorylate and activate $\mathrm{p} 53$ protein $[24,25]$. In agreement with these data, we found an increased phosphorylation of p53 protein at Ser33 regulated by p38 kinase. We also found that inhibition of $\mathrm{p} 38$ and JNK kinases prevents induction of p53 in cells in which E-cadherin was downregulated. These findings are consistent with animal studies showing an increased expression of $\mathrm{p} 53$ and $\mathrm{p} 21 / \mathrm{Waf1}$ proteins in murine gastric lesions where the E-cadherin $(\mathrm{CDH} 1)$ gene was conditionally deleted while concomitant knockdown of E-cadherin and p53 abrogates expression of p21, strongly increasing cell proliferation and gastric tumorigenesis in mice [20]. 
A

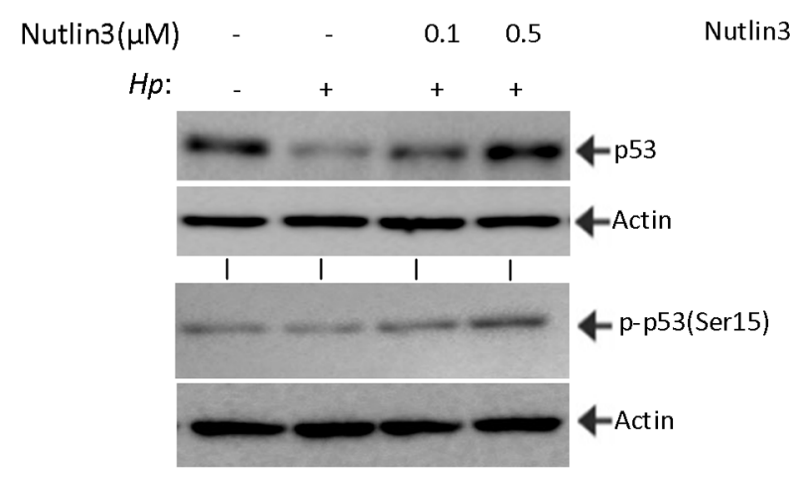

D
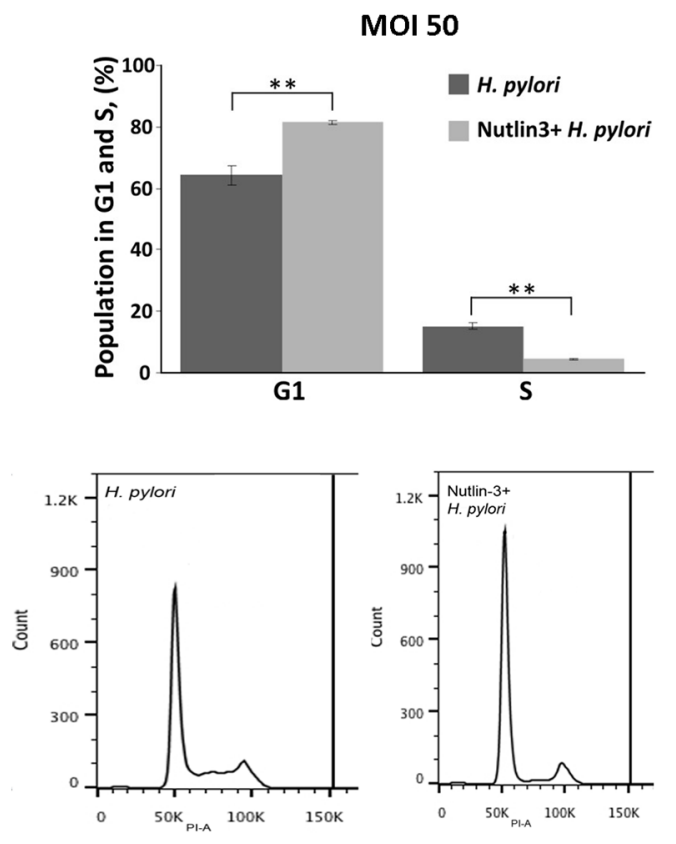

B

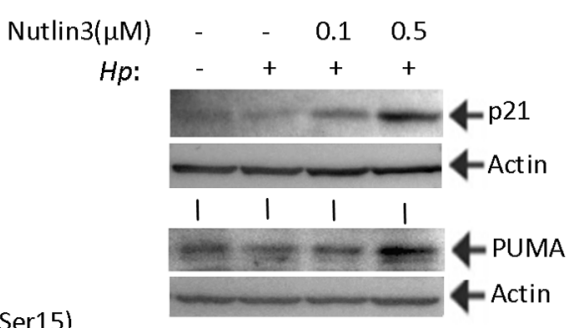

C

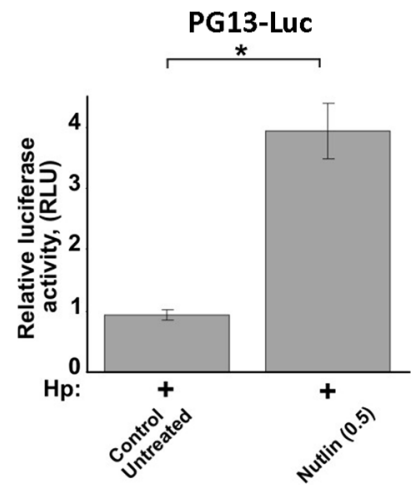

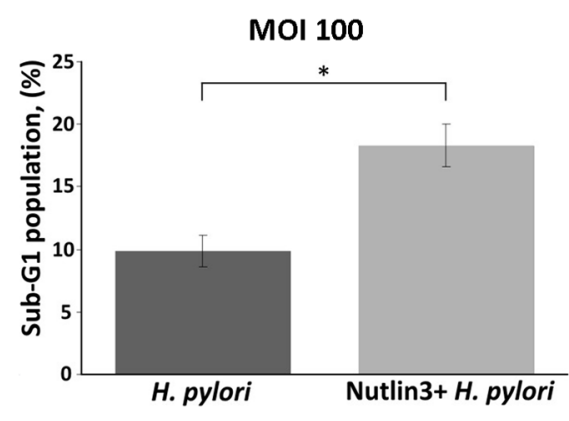

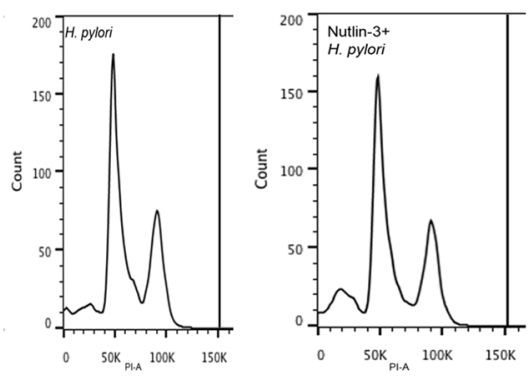

Figure 6: Nutlin-3 restores p53 activity and increases cell death of $\boldsymbol{H}$. pylori-infected cells. (A) Treatment with Nutlin-3 increases levels of p 53 protein and its phosphorylation at Ser15. STKM2 cells treated with the indicated concentrations of Nutlin-3 were co-cultured with $\mathrm{H}$. pylori strain 7.13 for 24 hrs and analyzed for expression of p53 protein (top) and its phosphorylation at Ser15 (bottom) by Western blotting. (B) The same as (A) but expression of p21 and PUMA proteins was analyzed. (C) STKM2 cells transfected with a p53 reporter plasmid (PG13-Luc) and treated with $0.5 \mu \mathrm{M}$ Nutlin-3 were co-cultured with H. pylori strain 7.13 for 24 hrs and analyzed using the dual-luciferase reporter assay. (D) STKM2 cells treated with $5 \mu \mathrm{M}$ Nutlin-3 or a vehicle were co-cultured with H. pylori strain 7.13 for $24 \mathrm{hrs}$ at MOI 50 or MOI 100 and then collected, stained with propidium iodine, and analyzed by flow cytometry. Bar graph shows changes in the $\mathrm{G} 1$ and $\mathrm{S}$ phases of the cell cycle (left panel; **, $p<0.01 ; n=3$ ). Right panel shows the percentage of cells in the sub-G1 fraction $(*, p<0.05 ; n=3)$. Bottom panels show flow cytometry profiles for the aforementioned experiments.

Studies conducted by us, as well as previous reports showed that $H$. pylori reduces E-cadherin protein levels and disrupts the adherens junctions [14, 15]. Exposure to H. pylori also induced p38 and JNK kinases. However, it does not lead to induction of p53. Our experiments (Figures 3 and 4) revealed that H. pylori prevents induction of $\mathrm{p} 53$ in gastric cells, in which E-cadherin was downregulated by increasing phosphorylation and activity of HDM2 protein. Inhibition of HDM2 with siRNA or Nutlin-3 suppresses H. pylori - induces degradation of $\mathrm{p} 53$. Testing of additional inhibitors of HDM2 such as stapled peptides may help to further dissect the mechanism by which H. pylori inhibits p53 [31]. 


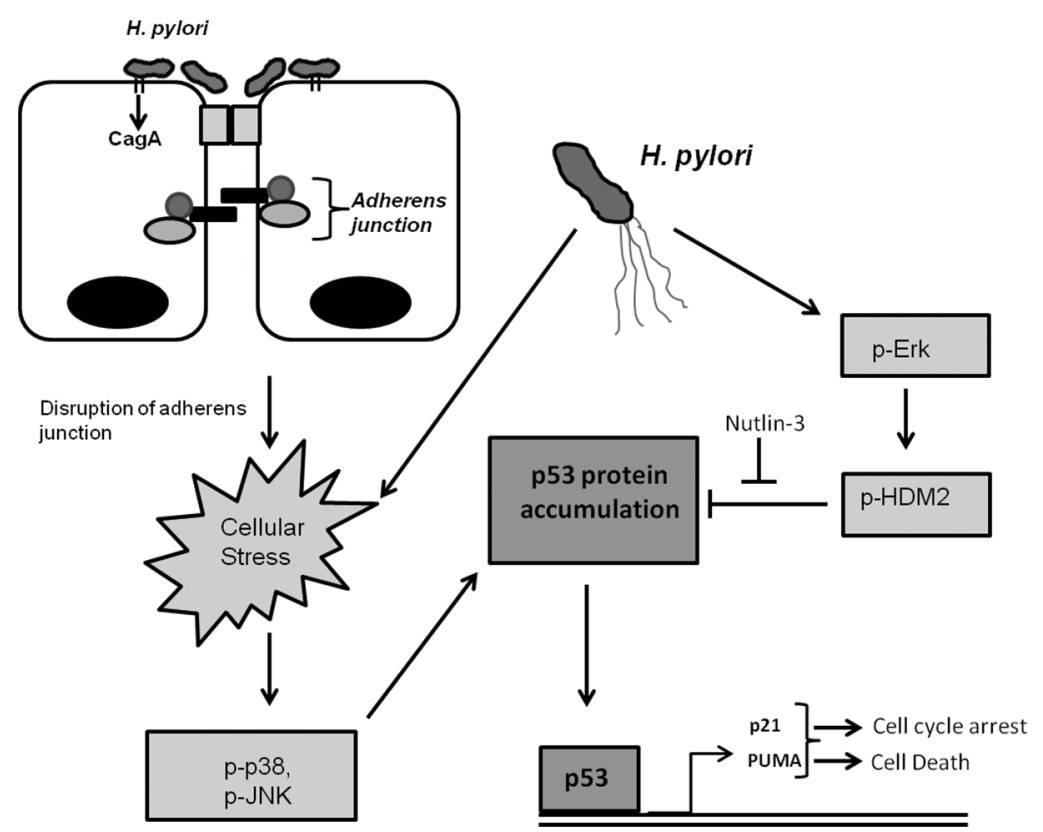

Figure 7: H. pylori alters p53 and E-cadherin signaling.

Interestingly, protein levels of HDM2 protein follow the dynamics of $\mathrm{p} 53$ downregulation suggesting that a feed back loop regulates levels of p53 and HDM2 proteins in $H$. pylori-infected cells [32]. Additional studies are needed to define this mechanism. We found that Erk kinases are responsible for an increased phosphorylation of HDM2 since its inhibition reduces HDM2 phosphorylation and increases levels of p53 in H. pylori-infected cells. Previous studies have reported that Akt kinase can also phosphorylate HDM2 in H. pylori-infected cells [33], suggesting that both Erk and Akt kinases contribute to activation of HDM2 and downregulation of $\mathrm{p} 53$.

These studies support previous findings that p53 is regulated in a CagA-dependent manner [33]. Indeed, ectopic expression of CagA increases phosphorylation of HDM2 and degradation of p53. Downregulation of HDM2 inhibits activity of CagA directed toward p53. We also found that $H$. pylori cag $A^{-}$or $c a g E^{-}$mutants are less potent in inhibition of p53 than that of wild-type. In regards to regulation of E-cadherin by $H$. pylori, both CagA-dependent and -independent mechanisms have been previously reported $[34,35]$. In our studies, we observed that although CagA is not absolutely required, its presence does increase the downregulation of E-cadherin.

H. pylori is known to preferably adhere to epithelial cells in close proximity to the apical-junctional complexes and target them possibly to gain access to essential nutrients or obtain entry to the lamina propria $[10,11]$. Disruption of epithelial barrier, however, is accompanied by significant alteration in cellular homeostasis and cellular stress, in which p53 is a key regulator of cell cycle and apoptosis. Inhibition of p53 may be advantageous for $H$. pylori as it reduces cell death and is associated with activation of the immune system, which recognizes and targets cells under cellular stress [36]. In support, we found that inhibition of HDM2 by Nutlin-3 in cells exposed to $H$. pylori restore $\mathrm{p} 53$ activity and significantly increase cell cycle arrest and cell death.

Taken together, our studies show that regulation of E-cadherin and p53 is tightly linked through the p 53 stress response mechanism. In the setting of $H$. pylori infection, this mechanism is inhibited as the bacteria modulate the p53 response through activation of the Erk1/2-HDM2 pathway that inhibits p53 in a CagA-dependent manner (Figure 7).

\section{MATERIALS AND METHODS}

\section{Cell cultures and $H$. pylori infection}

STKM2, AGS, SNU1, and HFE145 gastric cancer cells were maintained in RPMI 1640 medium (Invitrogen, Carlsbad, CA) supplemented with 10\% fetal bovine serum (FBS). Murine gastric epithelial cells (mGECs) were harvested from a transgenic mouse, bearing a temperaturesensitive mutant of SV40 large T antigen and cultured in RPMI 1640 medium with $10 \%$ FBS and interferon-gamma at permissive temperature $33^{\circ} \mathrm{C}$ [23]. One day before experiment, mGEC cells were maintained at $37^{\circ} \mathrm{C}$ and continued until experimental end point.

CagA-positive H. pylori clinical strain J166 and rodent adapted strain 7.13 [37] were grown in Brucella broth 
with 5\% FBS for 18 hours, harvested by centrifugation, and added to gastric cells at a bacteria-to-cell ratio of 100:1 (multiplicity of infection, MOI 100) unless otherwise mentioned. Isogenic cagA- and $\operatorname{cagE}^{-}$mutants were constructed within strain 7.13 by insertional mutagenesis using aphA and selection with kanamycin [37].

\section{Gerbil infection and western blotting}

All animal experiments and procedures were approved by the Institutional Animal Care Committee at Vanderbilt University. Pathogen-free Mongolian gerbils purchased from Harlan Labs (Indianapolis, IN) were challenged orogastrically with either sterile Brucella broth or rodent-adapted $H$. pylori strain 7.13. The animals were euthanized 6 hour post infection; gastric tissues were harvested and analyzed by Western blotting.

\section{Luciferase reporter assay}

PG13-Luc reporter plasmid has been described previously [38]. Luciferase activity was measured using the Dual Luciferase Reporter Assay Kit (Promega, Madison, WI) according to the manufacturer's protocol.

\section{Cell cycle and apoptosis analyses}

Cell cycle analysis was performed as described previously [9]. Briefly, STKM2 cells were seeded into a 6-well plate and treated accordingly. The cells were trypsinized, collected, washed twice with PBS and fixed in $75 \%$ ethanol for 2 hours at $4^{\circ} \mathrm{C}$. Cells were then washed twice with cold-PBS to remove ethanol and stained with propidium iodine (PI). The DNA content was measured by flow cytometry.

Apoptosis assay was performed using the Anexin V: PE Apoptosis Detection Kit I (BD Bioscience, San Jose, CA) according to the manufacturer's protocol.

\section{Plasmids, siRNA, antibodies, and chemical inhibitors}

CagA expression plasmid (CagA-pSP65SR $\alpha$ ) has been described previously [33]. E-cadherin siRNA and E-cadherin antibody were purchased from BD Bioscience. Antibodies to the following proteins were used in this study: p53 (DO-1), p21 (Ab-1), and HDM2 from Calbiochem (San Diego, CA); PUMA (ab9643) from Abcam Inc. (Cambridge, MA); p-MDM2(Ser166), JNK, p-p53(Ser33), p-p53(ser15), p-38, and p-p38(Thr180/ Tyr182) from Cell Signaling Technology (Danvers MA); p-Erk1/2(Tyr204), p-JNK(Thr183/Tyr185) from Santa Cruz Biotechnologies (Dallas, TX). Protein loading was monitored using the anti- $\beta$-actin antibody
(Sigma Aldrich, St. Louis, MO). Nutlin-3 was obtained from Sigma. Chemical inhibitor library was purchased from Selleckchem (Houston, TX). The following chemical inhibitors were used: p38 MAPK (SB203580), Akt(MK2206 2HCl), JNK/SAPK (SP600125), PKC delta (Go 6983), c-Met (PHA-665752), Rock-1 (Y-27632 2HCl), Rock-2 (Fasudil), Rock 1 and 2 (GSK429286A), FAK (PF-562271), PLK1 (Rigosertib), GSK3 $\beta$ (CHIR98014), Src (Saracatinib), PKA (H89 2HCl), Fyn (PP1), DUBS (PR-619), mTOR1 and 2 (KU-0063794), STAT3 (WP1066), PI3K (LY294002), and Rac1 (EHop-016).

\section{RNA extraction and qRT-PCR}

Total RNA was extracted using the Qiagen RNeasy kit. $1 \mu \mathrm{g}$ RNA was reverse transcribed using the HighCapacity cDNA Reverse Transcription Kit according to the manufacturer's protocol (Applied Biosystem, Grand Island, NY). qRT-PCR was performed as described previously [9] with the following specific primers using the iCycler (Bio-Rad, Hercules, CA): E-cadherin: TGG AGG AAT TCT TGC TTT GC, CGT ACA TGT CAG CCA GCT TC; p53: TAA CAG TTC CTG CAT GGG CGGC, AGG ACA GGC ACA AAC ACG CAC C; HPRT: TTG GAA AGG GTG TTTA TTC CTC A, TCC AGC AGG TCA GCA AAG AA.

\section{Statistical analyses}

Statistical analysis was performed using the Student's $t$-test. Results are expressed as averages \pm SEM, if not specifically indicated. Results were considered significant when $p$-value was equal to or less than 0.05 .

\section{ACKNOWLEDGMENTS}

We thank Dr. V. Polosukhin (Vanderbilt University, Nashville, TN) for providing help with imaging.

\section{Funding}

This work was supported by grants from the National Cancer Institute grant NIH CA138833, the Department of Veterans Affairs (AZ), Vanderbilt Ingram Cancer Center (P30 CA68485), the Vanderbilt Digestive Disease Research Center (DK058404), and CSTA award No. UL1TR000445 from the National Center for Advancing Translational Sciences. The contents of this work are solely the responsibility of the authors and do not necessarily represent the official views of the Department of Veterans Affairs, National Institutes of Health, or Vanderbilt University. 


\section{Conflict of interest}

The authors disclose no potential conflicts of interest.

\section{REFERENCES}

1. Kusters JG, van Vliet AH, Kuipers EJ. Pathogenesis of Helicobacter pylori infection. Clin Microbiol Rev. 2006; 19:449-490.

2. Atherton JC, Blaser MJ. Coadaptation of Helicobacter pylori and humans: ancient history, modern implications. J Clin Invest. 2009; 119:2475-2487.

3. Peek RM, Jr., Blaser MJ. Helicobacter pylori and gastrointestinal tract adenocarcinomas. Nat Rev Cancer. 2002; $2: 28-37$

4. Ohnishi N, Yuasa H, Tanaka S, Sawa H, Miura M, Matsui A, Higashi H, Musashi M, Iwabuchi K, Suzuki M, Yamada G, Azuma T, Hatakeyama M. Transgenic expression of Helicobacter pylori CagA induces gastrointestinal and hematopoietic neoplasms in mouse. Proc Natl Acad Sci U S A. 2008; 105:1003-1008.

5. Riley T, Sontag E, Chen P, Levine A. Transcriptional control of human p53-regulated genes. Nat Rev Mol Cell Biol. 2008; 9:402-412.

6. Demidenko ZN, Korotchkina LG, Gudkov AV, Blagosklonny MV. Paradoxical suppression of cellular senescence by p53. Proc Natl Acad Sci U S A. 2010; 107:9660-9664.

7. Matsumoto Y, Marusawa H, Kinoshita K, Endo Y, Kou T, Morisawa T, Azuma T, Okazaki IM, Honjo T, Chiba T. Helicobacter pylori infection triggers aberrant expression of activation-induced cytidine deaminase in gastric epithelium. Nat Med. 2007; 13:470-476.

8. Tsugawa H, Suzuki H, Saya H, Hatakeyama M, Hirayama T, Hirata K, Nagano O, Matsuzaki J, Hibi T. Reactive oxygen species-induced autophagic degradation of Helicobacter pylori CagA is specifically suppressed in cancer stem-like cells. Cell Host Microbe. 2012; 12:764-777.

9. Wei J, Noto J, Zaika E, Romero-Gallo J, Correa P, El-Rifai W, Peek RM, Zaika A. Pathogenic bacterium Helicobacter pylori alters the expression profile of $\mathrm{p} 53$ protein isoforms and p53 response to cellular stresses. Proc Natl Acad Sci U S A. 2012; 109:E2543-2550.

10. Wroblewski LE, Peek RM, Jr. "Targeted disruption of the epithelial-barrier by Helicobacter pylori”. Cell Commun Signal. 2011; 9:29.

11. Ito T, Kobayashi D, Uchida K, Takemura T, Nagaoka S, Kobayashi I, Yokoyama T, Ishige I, Ishige Y, Ishida N, Furukawa A, Muraoka H, Ikeda S, Sekine M, Ando N, Suzuki Y, et al. Helicobacter pylori invades the gastric mucosa and translocates to the gastric lymph nodes. Lab Invest. 2008; 88:664-681.
12. Terres AM, Pajares JM, O'Toole D, Ahern S, Kelleher D. $\mathrm{H}$ pylori infection is associated with downregulation of E-cadherin, a molecule involved in epithelial cell adhesion and proliferation control. J Clin Pathol. 1998; 51:410-412.

13. Brembeck FH, Rosario M, Birchmeier W. Balancing cell adhesion and Wnt signaling, the key role of beta-catenin. Curr Opin Genet Dev. 2006; 16:51-59.

14. O'Connor PM, Lapointe TK, Jackson S, Beck PL, Jones NL, Buret AG. Helicobacter pylori activates calpain via toll-like receptor 2 to disrupt adherens junctions in human gastric epithelial cells. Infect Immun. 2011; 79:3887-3894.

15. Hoy B, Lower M, Weydig C, Carra G, Tegtmeyer N, Geppert T, Schroder P, Sewald N, Backert S, Schneider G, Wessler S. Helicobacter pylori HtrA is a new secreted virulence factor that cleaves E-cadherin to disrupt intercellular adhesion. EMBO Rep. 2010; 11:798-804.

16. Liu YC, Shen CY, Wu HS, Chan DC, Chen CJ, Yu JC, Yu CP, Harn HJ, Shyu RY, Shih YL, Hsieh CB, Hsu HM. Helicobacter pylori infection in relation to E-cadherin gene promoter polymorphism and hypermethylation in sporadic gastric carcinomas. World J Gastroenterol. 2005; 11:5174-5179.

17. Chan AO, Peng JZ, Lam SK, Lai KC, Yuen MF, Cheung HK, Kwong YL, Rashid A, Chan CK, Wong BC. Eradication of Helicobacter pylori infection reverses E-cadherin promoter hypermethylation. Gut. 2006; 55:463-468.

18. Chan AO, Lam SK, Wong BC, Wong WM, Yuen MF, Yeung YH, Hui WM, Rashid A, Kwong YL. Promoter methylation of E-cadherin gene in gastric mucosa associated with Helicobacter pylori infection and in gastric cancer. Gut. 2003; 52:502-506.

19. Becker KF, Atkinson MJ, Reich U, Becker I, Nekarda H, Siewert JR, Hofler H. E-cadherin gene mutations provide clues to diffuse type gastric carcinomas. Cancer Res. 1994; 54:3845-3852.

20. Shimada S, Mimata A, Sekine M, Mogushi K, Akiyama Y, Fukamachi H, Jonkers J, Tanaka H, Eishi Y, Yuasa Y. Synergistic tumour suppressor activity of E-cadherin and p53 in a conditional mouse model for metastatic diffusetype gastric cancer. Gut. 2012; 61:344-353.

21. Keller G, Vogelsang H, Becker I, Plaschke S, Ott K, Suriano G, Mateus AR, Seruca R, Biedermann K, Huntsman D, Doring C, Holinski-Feder E, Neutzling A, Siewert JR, Hofler H. Germline mutations of the E-cadherin(CDH1) and TP53 genes, rather than of RUNX3 and HPP1, contribute to genetic predisposition in German gastric cancer patients. J Med Genet. 2004; 41:e89.

22. Oliveira C, Ferreira P, Nabais S, Campos L, Ferreira A, Cirnes L, Alves CC, Veiga I, Fragoso M, Regateiro F, Dias LM, Moreira H, Suriano G, Machado JC, Lopes C, Castedo S, et al. E-Cadherin (CDH1) and p53 rather than SMAD4 and Caspase-10 germline mutations contribute to 
genetic predisposition in Portuguese gastric cancer patients. Eur J Cancer. 2004; 40:1897-1903.

23. Whitehead RH, Robinson PS. Establishment of conditionally immortalized epithelial cell lines from the intestinal tissue of adult normal and transgenic mice. Am J Physiol Gastrointest Liver Physiol. 2009; 296:G455-460.

24. Sanchez-Prieto R, Rojas JM, Taya Y, Gutkind JS. A role for the p38 mitogen-acitvated protein kinase pathway in the transcriptional activation of p53 on genotoxic stress by chemotherapeutic agents. Cancer Res. 2000; 60:2464-2472.

25. Fuchs SY, Adler V, Pincus MR, Ronai Z. MEKK1/JNK signaling stabilizes and activates p53. Proc Natl Acad Sci U S A. 1998; 95:10541-10546.

26. Bulavin DV, Saito S, Hollander MC, Sakaguchi K, Anderson CW, Appella E, Fornace AJ, Jr. Phosphorylation of human p53 by p38 kinase coordinates N-terminal phosphorylation and apoptosis in response to UV radiation. EMBO J. 1999; 18:6845-6854.

27. Zhou BP, Liao Y, Xia W, Zou Y, Spohn B, Hung MC. HER-2/neu induces p5 ubiquitination via Akt-mediated MDM2 phosphorylation. Nat Cell Biol. 2001; 3:973-982.

28. Feng J, Tamaskovic R, Yang Z, Brazil DP, Merlo A, Hess D, Hemmings BA. Stabilization of Mdm2 via decreased ubiquitination is mediated by protein kinase $\mathrm{B} / \mathrm{Akt}$-dependent phosphorylation. J Biol Chem. 2004; 279:35510-35517.

29. Malmlof M, Roudier E, Hogberg J, Stenius U. MEK-ERKmediated phosphorylation of Mdm2 at Ser-166 in hepatocytes. Mdm2 is activated in response to inhibited Akt signaling. J Biol Chem. 2007; 282:2288-2296.

30. Hatakeyama M. Helicobacter pylori and gastric carcinogenesis. J Gastroenterol. 2009; 44:239-248.

31. Wei SJ, Joseph T, Chee S, Li L, Yurlova L, Zolghadr K, Brown C, Lane D, Verma C, Ghadessy F. Inhibition of nutlin-resistant HDM2 mutants by stapled peptides. PLoS One. 2013; 8:e81068.

32. Honda R, Yasuda H. Activity of MDM2, a ubiquitin ligase, toward p53 or itself is dependent on the RING finger domain of the ligase. Oncogene. 2000; 19:1473-1476.

33. Wei J, Nagy TA, Vilgelm A, Zaika E, Ogden SR, Romero-Gallo J, Piazuelo MB, Correa P, Washington MK, El-Rifai W, Peek RM, Zaika A. Regulation of p53 tumor suppressor by Helicobacter pylori in gastric epithelial cells. Gastroenterology. 2010; 139:1333-1343.

34. Suzuki M, Mimuro H, Suzuki T, Park M, Yamamoto T, Sasakawa C. Interaction of CagA with Crk plays an important role in Helicobacter pylori-induced loss of gastric epithelial cell adhesion. J Exp Med. 2005; 202:1235-1247.

35. Weydig C, Starzinski-Powitz A, Carra G, Lower J, Wessler S. CagA-independent disruption of adherence junction complexes involves E-cadherin shedding and implies multiple steps in Helicobacter pylori pathogenicity. Exp Cell Res. 2007; 313:3459-3471.

36. Raulet DH, Guerra N. Oncogenic stress sensed by the immune system: role of natural killer cell receptors. Nat Rev Immunol. 2009; 9:568-580.

37. Franco AT, Israel DA, Washington MK, Krishna U, Fox JG, Rogers AB, Neish AS, Collier-Hyams L, Perez-Perez GI, Hatakeyama M, Whitehead R, Gaus K, O'Brien DP, Romero-Gallo J, Peek RM, Jr. Activation of beta-catenin by carcinogenic Helicobacter pylori. Proc Natl Acad Sci U S A. 2005; 102:10646-10651.

38. Vilgelm AE, Washington MK, Wei J, Chen H, Prassolov VS, Zaika AI. Interactions of the p53 protein family in cellular stress response in gastrointestinal tumors. Mol Cancer Ther. 2010; 9:693-705. 


\section{SUPPLEMENTARY FIGURE}

A

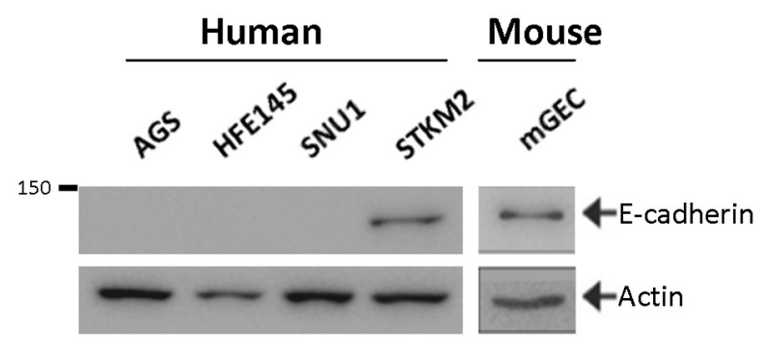

C

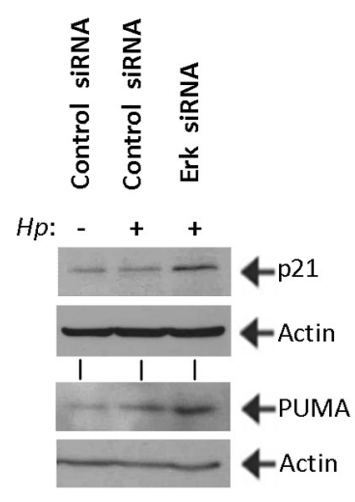

E

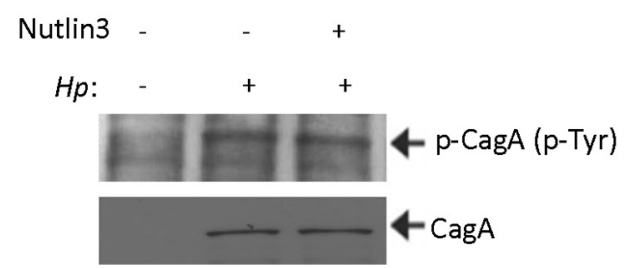

B
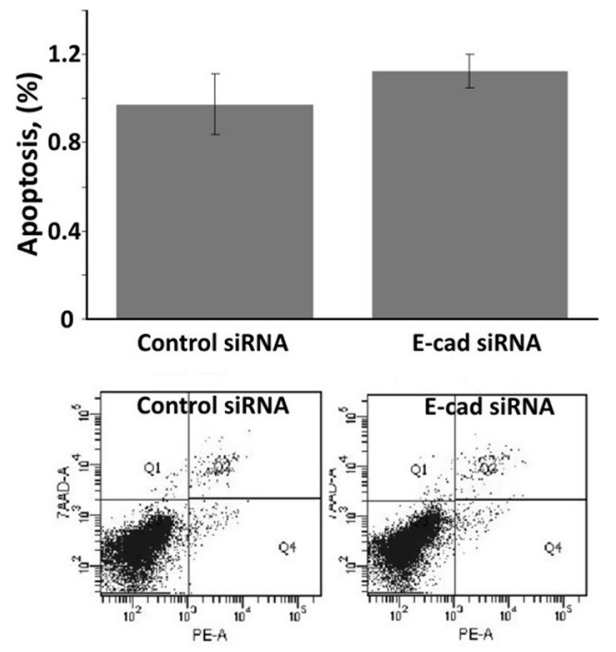

D

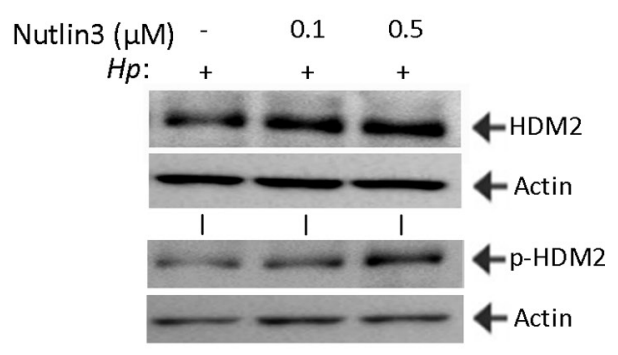

Supplementary Figure 1: (A) Western blot analysis of E-cadherin protein in gastric epithelial cell lines AGS, SNU1, HFE145 STKM2, and mGEC. (B) Analysis of cell death was performed on STKM2 cells transfected with E-cadherin or control scrambled siRNA for $48 \mathrm{hrs}$ by flow cytometry using the Annexin V staining. (C) Expression of p53 target genes (p21 and PUMA) was assessed after downregulation of Erk kinases with siRNA (48 hrs) in infected AGS cells. (D) Treatment with Nutlin-3 increases levels and phosphorylation of HDM2 protein at Ser166. STKM2 cells treated with the indicated concentrations of Nutlin-3 were co-cultured with H. pylori for 24 hrs and analyzed for expression of HDM2 protein (top) and its phosphorylation at Ser166 (bottom) by Western blotting. (E) Nutlin-3 does not affect delivery of CagA protein into host cells. Phosphorylation of CagA protein was used as a marker for its delivery into host cells. STKM2 cells treated with $0.5 \mu \mathrm{M}$ Nutlin-3 or left untreated were co-cultured with $H$. pylori strain 7.13 for 6 hrs and analyzed for CagA protein phosphorylation using phospho-tyrosine antibody. CagA protein was used as a loading control. 